\title{
RCS 组合框架结构节点受力机理及构造措施
}

\author{
杨志勇 岳秀勇
}

贵州省交通规划勘察设计研究院股份有限公司，贵州 贵阳 550088

[摘要] 现代建筑中, 组合结构的应用越来越普遍, 为充分挖掘组合结构中材料的优越性能, 对其受力机理及构造措施进行的 研究。本文以 RCS 组合框架结构节点受力类型作为切入点, 对钢筋混凝土柱一钢框梁受力机理进行分析和其构造措施进行论 述，以及简单阐述美国、日本等国家的构造措施，以期为后续 RCS 组合框架结构在实际工程中的运用提供参考。 [关键词] 组合结构; RCS 组合框架结构; 节点机理; 构造措施 DOI： 中图分类号：TU398.9 文献标识码：A

\section{Stress Mechanism and Construction Measures of RCS Composite Frame Structure Joints} YANG Zhiyong, YUE Xiuyong Guizhou Transportation Planning, Survey and Design Research Institute Co., Ltd., Guizhou Guiyang, 550088 China

\begin{abstract}
In modern architecture, the application of composite structure is becoming more and more common. In order to fully excavate the superior properties of materials in composite structure, the stress mechanism and structural measures are studied. In this paper, the stress type of RCS composite frame structure node is taken as the cut-in point, the stress mechanism of reinforced concrete column-steel frame beam and its structural measures are discussed.
\end{abstract}

Keywords: Combination structure; RCS composite frame structure; Mechanism of the node; Construction measures

\section{引言}

RCS 组合由钢材和钢筋混凝土构成, 可用于建筑楼面梁、板、柱等构件中, 兼具钢结构和钢筋混凝土结构的特点和 优势。目前对 RCS 组合结构节点受力机理的研究, 主要集中于承压能力、抗剪切、抗震性能等方面。本文以 RCS 组合 框架结构节点受力类型作为切入点, 对钢筋混凝土柱一钢框梁受力机理进行分析及其构造措施进行论述, 对比美国、 日本等相关构造措施，以期为后续 RCS 组合框架结构在我国的运用提供参考。

\section{RCS 组合结构节点受力特点}

\section{1 剪切力}

RCS 组合结构节点的剪切破坏, 即由于节点区域内钢梁腹板屈服, 导致节点混凝土剪切破坏, 其所受剪切力具有滞 后性、长期性特点。一般而言, 钢筋混凝土柱一钢梁组合结构作为坚向构件等承重构件, 既要承担来自风等水平方向 的力, 又要承担坚向荷载产生的作用力, 甚至可能出现地震作用产生的破坏力。为了抵抗水平外力（少数情况除外, 如地震导致结构损坏), 钢筋混凝土柱一钢梁组合结构的组合截面与外力产生相互剪切作用, 无论结构是否出现错动变 形, 都能产生的剪切力。若外力持续增大, 节点区域混凝土的开裂逐渐导致混凝土保护层剥落, 节点核心区暴露, 其 最大承载力是由节点区域钢梁腹板屈服及混凝土剪切破坏所控制。因此在实际运用中, 应防止钢筋混凝土柱一钢梁组 合结构节点出现剪切破坏。

\section{2 竖向力}

坚向力包括墙体自重, 也包括建筑垂直方向产生的作用力, 如图 1 所示为美国钢筋混凝土柱-钢梁组合结构贯通型 节点; 图 2 所示为日本 RCS 组合节点柱面钢板型大样, 钢梁不得整体连续穿过钢筋混凝土柱, 而只是连接在钢筋混凝 土柱节点区域的四周柱面钢板上:

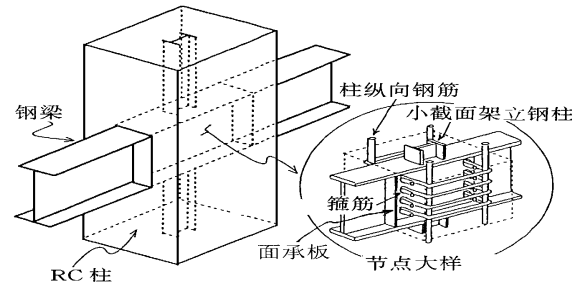

图 1 RCS 组合梁贯通型节点

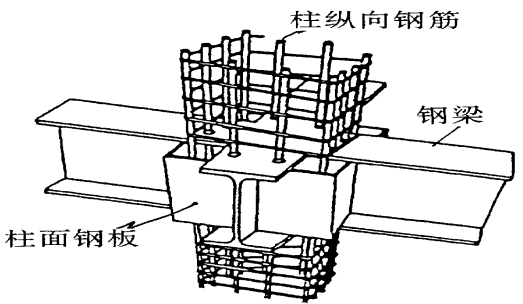

图 2 RCS 组合梁柱面钢板型节点 
RCS 组合结构节点混凝土承压破坏模式, 由钢梁翼缘对角上下方的混凝土局部压碎而引起。在钢筋混凝土柱一钢梁 组合结构贯通型节点中, 通过柱纵向钢筋、面承板和䈨筋进行坚向力的传递, 确保来自结构自身的坚向力及外部坚向 荷载能够借助钢筋、面承板等传递到整个承重系统中, 使得节点自身不会出现受压损坏。同时, 节点的整体设计采用 钢筋混凝土、型钢梁和小截面架立钢柱，使混合力、水平力以及单一的坚向力分别得到传导 ${ }^{[1]}$ 。

\section{3. 混合力}

混合力在现代建筑结构中最为常见, 且一般意义上的剪切力、坚向力也均是混合出现的, 只存在比例上的主导作 用。钢筋混凝土柱-钢梁组合结构应用于建筑结构时, 其所受力既包括上文所述的剪切力、坚向压力, 也包括一些较小 的扰动, 如室内活动等, 这些因素一般不会直接对钢筋混凝土柱-钢梁组合节点造成破坏, 但会持续叠加, 造成瞬间节 点、局部受力失衡的问题, 甚至导致小幅形变 ${ }^{[2]}$ 。较为典型的则是钢板结构形变, 当来自垂直方向和水平方向的力混合 时, 力的常规传导受到破坏, 可能产生局部受力不均问题, 并导致钢板出现形变, 形变未能恢复, 新的力平衡在形变 后结构的基础上产生，即可导致永久破坏 ${ }^{[3]}$ 。

\section{RCS 组合结构节点受力机理}

\section{1 钢梁腹板框架一钢筋混凝土柱结构}

RCS 组合结构节点受力机理存在差异，这种差异与设计方式、结构应用区域等存在关联。钢梁腹板框架一混凝土柱 结构多见于建筑内部, 可视作室内 RCS 组合结构节点受力的代表模式, 该结构的节点由混凝土柱、钢梁腹板、翼缘等 共同组成。与其他以钢筋混凝土为主要材料的框架结构相似, 钢梁腹板框架-混凝土的剪切力分配与结构的承重能力带 有直接关联, 钢梁腹板在力的传导、承重和抗剪切力方面起到主要作用, 相当于钢梁翼缘的 $10^{\sim} 20$ 倍。如果结构的承 重需求较高, 传力和导力途径较为复杂, 这就需要对钢梁翼缘的设计进行优化, 使其能够与节点形成一个更紧密的整 体, 而型钢部分所需承担的剪切力, 则通过内部设计使其完全转移至钢梁腹板位置。上述设计的细节差异不会从根本 上影响节点受力机理, 即钢梁翼缘和面承板仅承担很小的力 (包括剪切力和混合力), 主要的承力和传力、导力均借助 钢梁腹板进行。

\section{2 混凝土斜压结构}

RCS 组合结构节点的主体部分一般为混凝土结构, 从受力机理的角度来看, 混凝土斜压结构的作用较为特殊。水平 方向的作用力和反作用力, 可借助面承板等进行扩散, 避免节点局部持续受压。同时, 钢梁的翼缘、面承板可将受到 的力传递至对应区域以实现力平衡, 对抗剪切力可能带来的破坏, 该方式被称为内部混凝土斜压杆机构, 是钢筋混凝 土柱一钢梁组合结构节点受力的典型方式。为保证对力的约束作用, 通过对钢梁翼缘、箍筋等进行评估, 确保实现力 的平衡, 同时通过力的传导和分散提升结构总体的承重能力。内部混凝土斜压杆机构对结构总体的承重影响, 可表现 为:

$$
W=f_{c} b_{p} \cos \theta
$$

式中 W 代表影响系数, $b_{p}$ 代表面承板的宽度参数, $f_{c}$ 代表斜压杆受力的长度, 为一个变量, $\theta$ 代表斜压杆轴线位 置、水平力方向之间的夹角。

\section{RCS 组合框架结构节点构造措施}

\section{1 美国 RCS 组合框架结构节点构造措施 ${ }^{[4]}$}

美国的 RCS 组合框架结构都是按照美国土木工程师协会于 1994 年制定的 RCS 框架中间层中节点和中间层边节点设 计指南的建议, 采用钢梁贯通的节点构造方案, 即钢梁连续穿过钢筋混凝土柱, 钢梁之间的连接点设在离梁柱节点区 较远的跨中受力较小处, 这样就免除了在受力较大的节点附近焊接或螺栓连接钢梁的不利做法。为了加强节点区域, 可根据具体工程的特点有选择采取以下一些构造措施： a. 扩大面承板； b. 在钢筋混凝土柱中设置架立钢骨，沿柱全高 设置的架立钢骨能在施工阶段与钢梁组成临时钢框架, 起到承担部分施工荷载的作用, 实现了 RCS 组合结构的立体施 工; c. 在钢梁翼缘上设置纵向钢筋, 以防混凝土局部压碎, 在节点区范围内的钢梁翼缘上设置抗剪栓钉。采用美国的 这套钢梁贯穿型节点构造方案的 RCS 梁柱节点具有刚度大、整体性好、极限承载力高的特点, 由于钢梁穿过节点, 以 及节点外围的加强构件 (如面承板等) 的作用, 使节点核心区混凝土被分割成若干小块, 每一小块都处于核心区钢梁 腹板、上下翼缘和节点外围加强构件的约束之中, 从而使节点核心区混凝土近似处于三向受压状态, 提高了混凝土的 抗压、抗剪能力, 从而增大了节点的极限承载力。 


\section{2 日本 RCS 组合框架结构节点构造措施 ${ }^{[4]}$}

日本 RCS 组合结构节点构造与美国不同, 其设计考虑的因素更多, 强调综合分析节点强度、刚度, 并考虑节点周 围结构的工作需求, 将变性能力、滞回能力纳入到分析范畴之内。当前日本 RCS 组合结构节点构造通常采用的都是柱 贯通型构造方案, 这一方案将钢筋混凝土柱的纵向钢筋贯通穿过节点, 钢梁采取适当的措施连接于节点上。为了便于 柱的纵向钢筋贯穿节点, 常常要将进入节点范围后的钢梁翼缘切断, 而通过较厚的面承板将翼缘置换成坚直设置的中 板, 这一节点形式同时兼顾了混凝土的浇捣方便和钢板对核心混凝土的约束效应。日本 AIJ 的 RCS 组合结构分会所编 制的《RCS 组合节点设计准则》将上述梁柱节点归类总结为 12 种标准类型, 包括柱面钢板型、面承板型、扩大的面承 板型、内镶或外露横隔板型及局部钢骨混凝土梁型等。

\section{3 钢梁的厚度和宽度均衡增加的构造措施}

厚度和宽度的均衡增加, 是指 RCS 组合结构节点构造时, 在空间条件允许的情况下, 设法提升混凝土钢筋用量, 并提升其与建筑其他承重、受力结构的整体性, 提升力的分散和传导效果。如在建筑转换层中, 将钢梁翼缘与钢筋混 凝土结构自 RCS 组合结构节点向外部延伸, 与混凝土柱、框架转换梁等连接为一个近似的整体结构, 来自建筑上部的 负载, 可得到转换梁、RCS 组合结构节点的共同承担, 不会过度集中于某一个结构处。来自水平方向的力, 也可以借助 优化后的结构得到均匀分散, 避免梁板受到瞬时剪切力破坏, 导致形变等问题。设计过程中应避免 RCS 组合结构节点 厚度和宽度的无限制增加, 降低结构自重的负面影响。构造选取方面, 以钢筋材料为例, 应在进行建设前核准型号, 并确保钢筋无氧化等问题。

\section{总结}

综上, RCS 组合结构节点受力机理相对明确, 构造措施也具有持续优化的空间。剪切力、坚向力、混合力是 RCS 组合结构节点受力的三个主要类型, 其受力机理应从三个方面着手分析, 包括钢梁腹板框架-框架结构、混凝土斜压结 构等等。因不同 RCS 组合结构节点的作用存在差异, 其构造措施上缺乏统一标准, 可参考美国、日本等发达国家经验, 但笔者认为我国不宜盲目照搬, 而应在国外已有的节点构造技术的基础上, 研制出适合我国施工环境的新型 RCS 梁柱 节点构造, 为我国 RCS 组合框架结构设计提供依据, 以综合保证组合节点受力的安全性及抗震性能。

\section{[参考文献]}

[1] 郭维明, 才子坤, 陈士军. 预制装配式 RCS 组合结构框架的静力弹塑性分析 [J]. 中外建筑, 2018 (12) : 147-148.

[2] 曾李生. 浅析采用钢一混凝土组合结构解决高支模施工问题 [J]. 工程建设与设计, 2018(17): 238-240.

[3] 熊礼全, 王培培, 郭正超, 等. 钢筋混凝土柱一钢梁组合节点抗剪承载力分析 $[\mathrm{J}]$. 建筑结构, 2016, 46 (13): 80-85.

[4]易勇.钢梁一钢筋混凝土柱组合框架中间层节点抗震性能试验研究 [D]. 重庆: 重庆大学, 2005.

作者简介: 杨志勇 (1990-), 男, 湖南郡阳人, 硕士研究生, 主要从事大跨度及高层钢、混凝土结构设计。 